\section{The Roper Center: A National Archive of Public Opinion Research}

\author{
Brinton Rowdybush \\ American Political Science Association
}

\section{Background}

In 1946, the Roper Center was established at Williams College through the joint efforts of Elmo Roper and James Phinney Baxter, the President of Williams College. As a professional historian, Baxter understood the potential value of a repository of public opinion data. The collection initially began with 177 surveys that had been conducted by Roper Research Associates. Several other pioneers in the field, including George Gallup, Sr., helped to increase the original holdings of the Center by donating their own survey materials.

For twenty years the Center remained at Williams College; however, in 1975 the trustees and staff of the Center undertook a reappraisal of their organizational structure and institutional affiliation. As a result, the Roper Center became a nonprofit corporation and in 1977 the archive and administrative offices moved to the University of Connecticut at Storrs where they are still located.

\section{Holdings}

The mission of the Roper Center is to function as the comprehensive library of public opinion research. The archive now includes over 11,000 separate studies conducted by major survey organizations in over 75 countries. For the United States the Center receives most of the commercially available data from the leading survey research organizations and the media. These add over 500 surveys a year to the archive. Among the holdings, for example, are extensive materials from: $A B C$ News, ABC News/Washington Post, CBS News, CBS News/New York Times, the New York Times, Gallup, the General Elec- tric Quarterly Surveys, the Los Angeles Times, NBC News (and with Associated Press and the Woll Street Journal), the $\mathrm{Na}$ tional Opinion Research Center (NORC) General Social Survey (GSS) studies, and the Roper Organization surveys. These organizations and many others have been generous in their contributions of complete datasets to the Center. In the event the data sets are not available, the Center acquires partial survey results in report or release form.

Foreign holdings are continually being expanded. The largest and most up-todate collecions include research by Brule Ville Associates in France, Social Surveys Limited in Great Britain and the Canadian Institute of Public Opinion. Also, several of the principal American survey research organizations have recently begun to cooperate with foreign colleagues to examine how opinion on a series of topics varies between two countries and surveys of this type have been conducted in Mexico and Japan. The Center has already received some of this data and anticipates continued additions in this area.

\section{Membership and Fees}

Membership in The Roper Center is through the International Survey Library Association (ISLA) created in 1964 as an organizational network of data users. Data and services for ISLA members are at a significant reduction from charges to nonmembers. Moreover, the membership and service fees for academic and educational institutions are at preferential rates. An academic institution can become an ISLA member for as little as $\$ 1,200$ per year and access to the POLL (Public Opinion Location Library) database (see below) is $\$ 300$ annually for members and $\$ 600$ annually for nonmembers. There is an hourly connect charge of $\$ 20-25$ for accessing the data. A researcher is not charged for the number of times the database is accessed, the number of searches done, or the quantity of data retrieved. 


\section{Services}

Four different products/services are available to clients: machine readable datasets, customized searches, dataset analysis, and the POLL. In 1987 the Center prepared and sent out more than 500 individual studies as a result of dataset requests. The majority of these were for academics who wished to pursue more detailed analysis of a given subject matter.

Customized searches are a second serv. ice of the Center and over 300 were carried out last year. They furnish all survey work done on a particular issue by any of the contributing organizations. A computer printout and/or individual pages provide each question and its full national responses. Information on the surveying organization, sample size, interview data, method of interviewing, and survey sponsor, if applicable, is specified. The Center does a customized data package for Public Opinion magazine and since 1978 the Roper Center has been responsible for most of the material in the "Opinion Round-up" section of the magazine. A cost estimate based on the staff hours necessary to complete a job can be provided free of charge. A complete fee schedule is available from the Center's Assistant Director for User Services and Administration.

A third service is computer analysis. For any user, there is a question of resources and economy. In a number of cases, for example breaking down a national figure into gender or ethnic groups, analysis can be performed more economically by Center staff than by outright purchase of a dataset. And should an inquirer not have the equipment to analyze a dataset, then ordering analysis is the only alternative.

The Public Opinion Location Library (POLL) is the fourth service of the Roper Center. It is an online database of survey research that first became available in July 1986 and has seen significant use, especially by the electronic and print media where time is a critical factor.

In order to be entered into the POLL database, data has to meet three criteria. First, it must be the result of scientific survey research methods. Second, the data has to be for a representative national population sample. Although the archive maintains data from special samples, these are not included in POLL. And third, there must be the complete text of questions and response categories. Unless these criteria can be met, the data are not eligible for the POLL database.

POLL is updated on a daily basis and is designed to let the user search the holdings of public opinion data utilizing four indexes: topics, words, organizations, and dates. The indexes can be used alone or interactively. POLL is divided into 105 topics and these can be refined using the word index. Further definition can specify data collected only by particular organizations. The final index, date, allows the user to request when a question was most recently asked, or the responses to the same question between 1981 and 1983 .

A search involving all of the indexes could look something like this:

\section{find topic presidency}

result: 7,207 items

\section{and word Reagan}

result: 3,489 items

\section{and organization gallup result: 279 items}

\section{and date after 1986} result: 67 items

The system allows for the use not only of the four indexes, but also three connectors: "and," "or," and "and not" (which permits more extensive manipulation of the files). The Center has prepared a POLL users manual that is available to POLL subscribers and other interested parties.

\section{Future Plans}

The Roper Center intends to continue to develop its resources and services which have already made it the most comprehensive source of polling data in existence. By 1991, it anticipates having the majority of its holdings of national surveys on-line in the POLL database. In addition, efforts are underway to include state polls in the archives as this information is of 
increasing interest to the academic and media communities.

It is proposed that the Center extend its holdings to the world's major industrial democracies. Collections are already underway for the United States, Canada, Great Britain, and France, and the expansion of holdings for West Germany, Italy, Japan, and other countries would be invaluable for students and scholars engaged in comparative studies of social, economic, and political developments.

A more active publications program is also envisioned. Center staff are presently working on the creation of a bi-monthly newsletter that would report on public opinion trends, data acquisitions, new survey work, and developments in Center services. A quarterly, POLL NEWS-
LETTER, began appearing in the Fall of 1987 and provides ideas for search strategies, indicates what survey materials have been added to the database, and shares information from those using POLL. Finally, the Center is maintaining its educational outreach program such as the fifth annual Public Opinion Program for Journalists which took place at Williams College in Massachusetts in June 1988. The Center was also represented at the APSA annual meeting in Washington in September 1988.

Inquiries about The Roper Center should be addressed to: John M. Barry, Manager, User Services Development, P.O. Box 440, Storrs, CT 06268; phone (203) $486-4440$.

\section{Announcing...}

The 1986 Guide lists over 300

Ph.D. and Masters programs in political science in both the U.S. and Canada. The description of each program includes information about specialization(s), tuition charges and financial aid, admission and degree requirements.

The Guide also lists over 4,900 faculty, by name, with their highest degree, fields of specialization, and current positions. The Guide has a faculty and geographical index and comprehensive data for each program on student admissions, enrollments, number of degrees awarded, and affirmative action efforts.

The price is $\$ 15$ for APSA members and $\$ 20$ for nonmembers.

\section{ORDERS MUST BE PREPAID.}

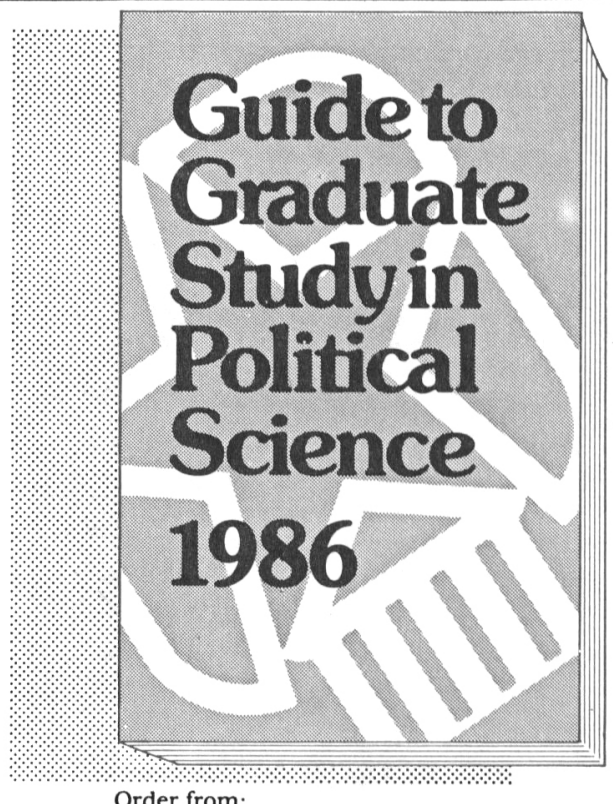

Order from:

Publications/APSA

1527 New Hampshire Avenue NW Washington, D.C. 20036 